\title{
A gestão democrática nas escolas públicas estaduais em Alagoas: um olhar com base nos marcos regulatórios
}

\section{Rosilânia Macedo da Silva ${ }^{1}$ e Jacqueline Lemos Fontes Silva Costa ${ }^{2}$}

\begin{abstract}
1 Mestre em Educação pela Universidade de Aveiro. Pedagoga e pós-graduada em Inspeção Educacional pela Universidade Federal de Alagoas. Inspetora Educacional no sistema municipal de ensino de Maceió, Coordenadora do Curso de Pós-Graduação em Inspeção Educacional no Centro Universitário Tiradentes, Brasil.

E-mail: rosilaniamacedo@hotmail.com http://lattes.cnpq.br/8415911086224041 iD http://orcid.org/0000-0003-3043-9762
\end{abstract}

2 Especialista em Inspeção Educacional pelo Centro Universitário Tiradentes e graduada em Pedagogia pela Universidade Estadual de Alagoas. Servidora pública da Secretaria de Estado de Educação de Alagoas, Brasil.

E-mail: jac_lemos@hotmail.com (9) http://lattes.cnpq.br/5416714698479285

RESUMO: Este artigo tem por objetivo analisar a legislação educacional que se reporta à gestão democrática em Alagoas, verificando as possíveis contribuições e entraves desse modelo na escola pública estadual naquele estado da federação brasileira. Realizado através da pesquisa bibliográfica e documental, se enquadra na abordagem qualitativa. Com base na legislação educacional nacional, ao exemplo da Lei de Diretrizes e Bases da Educação Nacional no 9.394 de 20 de dezembro de 1996 e, principalmente, a partir de estudos do arcabouço dos normativos que nortearam a construção da gestão democrática em Alagoas, este trabalho foi desenvolvido a partir da pesquisa documental. É com base nesse arcabouço que buscamos sustentação para alcançar os objetivos pretendidos. Assim, foi possível perceber que em Alagoas foram elaborados normativos em consonância com legislação nacional e de acordo com a configuração sociopolítica da sociedade brasileira, promovendo o estabelecimento de marcos regulatórios que viabilizaram iniciativas locais voltadas para uma gestão escolar com níveis mais ampliados de participação social. Esse modelo de gestão representou significativo corte no modelo mandatário anteriormente radicado nas escolas públicas estaduais em Alagoas, sem contudo, ser a solução para erradicação dos problemas educacionais que as escolas públicas educacionais trazem ao longo dos anos de educação formal no Estado.

Palavras-chave: Legislação educacional. Gestão democrática. Escola pública.

\section{The democratic management within state public schools in Alagoas}

ABSTRACT: This article aims to analyze the educational legislation that refers to democratic management in Alagoas, verifying the possible contributions and obstacles of this model in the state public school in that state of the Brazilian federation. Carried out through bibliographical and documentary research, it fits the qualitative approach. Based on the national educational legislation, to the example of the Law of Directives and Bases of the National Education no 9.394 of December 20, 1996 and, mainly, from studies of the normative framework that guided the construction of the democratic management in Alagoas, this work develops documentary research. It is on the basis of this framework that we seek sustainability to achieve the intended objectives. Thus, it was possible to perceive that normatives in Alagoas were elaborated in consonance with national legislation and according to the socio-political configuration of the Brazilian society, promoting the establishment of a regulatory framework which promote local projects targeting a broader and more participative school management. This management model represented a radical and significant cut in the mandated model previously established in the state public schools in Alagoas, without, however, being the solution to eradicate the educational problems that public educational schools bring throughout the years of formal education in the state.

Keywords: Educational Legislation. Democratic management. Public school 


\section{INTRODUÇÃO}

A Constituição Brasileira de 1988 instituiu a "democracia participativa", garantindo à educação, autonomia da escola e a gestão democrática. A discussão referente à gestão escolar se faz cada vez mais necessária para entender como se dá esse processo, ainda mais quando se trata da implantação da gestão democrática, em decorrência dos desafios de ordem social e das exigências de competências técnicas e políticas que esse processo requer.

A gestão democrática educacional, instituída pela Carta Magna, é uma das maiores conquistas dos direitos de cidadania no Brasil, e cabe lembrar que ela legitima a participação da comunidade escolar na definição de seus rumos, possibilitando a construção de uma educação de qualidade, enquanto direito de todos.

O fato é que, apesar de ter sido instituída, a gestão democrática nas escolas enfrenta resistências, porquanto nem todos entenderam e assumiram o processo democrático, tendo como centro a participação, a responsabilidade pelas decisões e seus resultados, estes configurando-se possíveis tensões, limitando ou impedindo a real efetivação da democratização da gestão escolar.

Este trabalho que tem por objetivo analisar a legislação educacional que se reporte à gestão democrática, verificando as possíveis contribuições e entraves desse modelo na rede pública estadual de Ensino em Alagoas, relacionados com a participação da comunidade escolar no processo de construção do princípio democrático em suas respectivas unidades de ensino.

Este estudo está divido em quatro partes. Além da introdução, reflexão final e refe- rências, encontramos alguns pontos relativos a gestão democrática do ensino público quanto a legislação educacional no Brasil, em seguida uma análise da democracia como um princípio da gestão nas escolas públicas. No que diz respeito a apresentação do estudo, é apresentada a trajetória da gestão democrática em Alagoas e os documentos que permitiram e nortearam sua implantação.

\section{A GESTÃO DEMOCRÁTICA À LUZ DA LE- GISLAÇÃO EDUCACIONAL NO BRASIL}

É inconcebível pensar em gestão da educação, sem considerar seu processo de construção social e político, que historicamente vem se constituindo e se firmando, à medida que, homens e mulheres, envolvidos na dinâmica de uma sociedade dialética, transformam, de forma cada vez mais ampla e complexa, o cenário social, substituindo teorias e práticas anteriores por novos paradigmas, produzindo e fazendo circular novos conhecimentos científicos e tecnológicos.

O movimento de redemocratização do país é um marco nessas transformações e na busca por uma sociedade mais justa e participativa. Sobretudo no que diz respeito à escola e sua importância para efetivação dos direitos e mudanças conquistados com a promulgação da Constituição de 1988. Conforme Silva $(2016$, p. 7):

A gestão democrática no Brasil foi institucionalizada como um princípio legal - regra básica adotada pela legislação a ser vivenciada tanto pela população como pelos governantes - através da Constituição Brasileira no ano de 1988, em seu artigo 206, inciso $\mathrm{VI}$, onde reza que essa nova forma de administrativa escolar será ministrada no ensino público, na forma da lei. 
Diante dessa perspectiva a gestão escolar não podia mais ser concebida como outrora. Nos anos 90, após várias discussões chegamos à Lei de Diretrizes e Bases da Educação Nacional (LDBEN) (BRASIL, 1996) que reafirma em seu art. 3으, inciso VIII, o modelo de gestão democrática na escola pública como um princípio. Coloca-se então, que, já não cabe administrar a escola monopolizando as decisões, num jogo em que uns pensam e decidem, enquanto outros, apenas executam. É preciso mudar, não apenas conceitualmente, mas, sobretudo, construir um novo pensamento sobre os espaços sociais, que se constituem coletivos e de coparticipação, de gestão democrática.

Logo em seguida da homologação da LDBEN 9394/96, o Plano Nacional de Educação (PNE) (BRASIL, 2001), aprovado pela Lei $\mathrm{n}^{\circ}$ $10.172 / 2001$, os seus objetivos, vem corroborar e reafirmar a importância da gestão democrática da escola pública para "promover a efetiva desburocratização e descentralização da gestão nas dimensões, pedagógica, administrativa e de gestão financeira". (BRASIL, 2001).

O Plano Nacional de Educação (PNE) (2014/2024), Meta 19, traz o texto:

(...) para a efetivação da gestão democrática da educação, associada a critérios técnicos de mérito e desempenho e à consulta pública à comunidade escolar, no âmbito das escolas públicas, prevendo recursos e apoio técnico da União para tanto. (BRASIL, 2014)

Silva (2016), com base nessa Meta 19, afirma que o referido instrumento regulador traz novas perspectivas sobre a forma de escolher os gestores da escola pública, que é a escolha associada a critérios técnicos de mérito e à consulta pública à comunidade escolar. Essas perspectivas, segundo a auto- ra (idem) irão interferir, sobremaneira, na estrutura que se tem, pois assim compreende:

\begin{abstract}
que o texto já define como deve ser o modelo para a escolha e nomeação do diretor. Podese interpretar a meta como que a eleição para diretores escolares, concursos públicos para cargo público efetivo de diretor escolar e indicação política poderão não ser mais utilizadas. Bem como não dá tanta autonomia aos sistemas para definir a forma de nomeação desse profissional. Ao que parece, vão se dá maior importância para nomear-se profissional a partir de seu desempenho, do nível de formação e da apreciação da comunidade. (SILVA, 2016, p.10).
\end{abstract}

Percebe-se que ainda há muito o que se discutir e debater sobre a escola democrática e sobre o princípio de gestão da instituição escolar pública. Há, portanto, que se considerar que deve existir um novo jeito de gerir os espaços públicos educacionais que extrapolem as práticas autoritárias já conhecidas. Se faz urgente entender os conceitos que envolvem esse processo, pois os parâmetros idealizados se difundem e se concretizam (COSTA; ROCHA, 2011). Por isso, a gestão democrática da educação necessita ser compreendida gradativamente e cada etapa de sua implantação e implementação ser estudada e fundamentada na legislação que a regula.

\section{DEMOCRACIA: O PRINCÍPIO DA GESTÃO NAS ESCOLAS PÚBLICAS}

A fase embrionária da gestão democrática teve início com os movimentos sociais durante o período de ditadura militar e foi contemplada anos depois na Constituição Brasileira de 1988. Nestes termos, cabe definir democracia refletindo sua significação 
no contexto educacional, a partir dos elementos políticos e sociais que a caracteriza:

Democracia é o regime político de soberania popular, porém com respeito integral aos direitos humanos. A fonte de poder está no povo que é radicalmente o titular da soberania e que deve exercê-la - seja através de seus representantes, seja através de formas diretas de participação nos processos decisórios. (BENEVIDES, 2002 apud HORA, 2007)

De fato, como a própria definição pressupõe, a democracia demanda participação efetiva nos processos decisórios, a fim de proporcionar a todos a igualdade de condições. Nossa legislação, como já visto neste estudo, assegurou a gestão democrática na escola como princípio e impulsionou-a como processo, sobretudo, nos anos 90, caracterizada, principalmente, pela participação da comunidade (BRASIL, 1988; BRASIL, 1996).

Aos princípios constantes na legislação quanto à educação democrática, como apoio em Silva (2015, p. 118) compreendemos como "Valores básicos do Estado democrático a serem adotados tanto pelos governos como pela população, e norteadores das legislações posteriores." É bem verdade que há controvérsias a esse modelo, pois é apontado por autores como sendo influência da globalização e do neoliberalismo (SILVA, 2012). Não podemos discordar, mas, podemos ainda afirmar que houve significativa relevância no cenário de mudanças na educação. O princípio democrático na gestão das escolas considerou a necessidade de pensá-la nas suas especificidades, de modo a superar o centralismo administrativo que predominava.

Perceber a escola como lócus em que o coletivo é a "mola mestra" para a promoção da equidade social e que os interesses individuais devem estar no âmbito do querer do direito fundamental para a oferta de uma educação de qualidade, é vislumbrar a prática do princípio democrático. E como afirma Paro $(2002$, p. 3) o princípio democrático e as concepções sobre democracia precisam ser entendidos "para além de seu sentido etimológico de governo do povo ou governo da maioria, para incluir todos os mecanismos, procedimentos". Neste caso, é principalmente considerar a intencionalidade das ações educativas para a formação do ser humano integrado ao mundo globalizado, objetivando transformações "intra-ser": Consigo mesmo; e "extra-ser": ser humano com outros seres humanos e com o planeta nas relações educativas, sociais, culturais e políticas. Esta convivência participativa deve sobrepor-se aos conflitos de intolerância, desrespeito e dente outros, a dominação, e ter como horizonte a prática democrática. Pois são esses "esforços e recursos que se utilizam, em termos individuais e coletivos, para promover o entendimento e a convivência social pacífica e cooperativa entre sujeitos históricos." (PARO, 2002, p. 3).

Nessa relação entre educação e sociedade, é necessário construir uma visão crítica do processo da administração escolar, a qual exige um conhecimento das estruturas socioeconômicas da sociedade de base capitalista, buscando compreender como a educação pode ser força propulsora de transformações sociais, realizadas a partir da consciência de homens e mulheres que participam das tomadas de decisões coletivas no processo educativo.

Entende-se, assim, que a gestão democrática nas escolas pode ser um meio para superação das relações de poder arbitrárias à consecução da autonomia dos sujeitos e, 
consequentemente, dos espaços em que se inserem. Outrossim, caracteriza-se pela articulação dos diversos segmentos das instituições para promoção de cidadãos conscientes das suas responsabilidades sociais.

Os princípios da democracia contemplados na Carta Magna e na LDBEN 9394/96, marcam uma redefinição dos papéis na gestão educacional e responsabilização coletiva pelo fazer da escola. De acordo com Hora (2003, p. 50), isto implica na "participação de todos os componentes da comunidade escolar nos processos decisórios e a existência de um amplo processo de informação em que todos tenham conhecimento do que acontece no interior da instituição e suas relações externas". Portanto, não há como pensar a escola sem que esta seja vista como uma unidade social, com suas características peculiares e as condições sociais que a definem. Conhecer essa realidade é fundamental para entender os problemas e dificuldades do dia a dia e, assim, poder se pensar em alternativas que ajudem no desenvolvimento pleno de cada instituição de ensino. Dessa maneira, torna a gestão democrática firmada pela participação coletiva da comunidade como um marco fulcral para que haja as mudanças necessárias à realidade individual de cada unidade de ensino.

\section{METODOLOGIA}

Trata-se de uma pesquisa exploratória de caráter bibliográfico e documental. Quanto ao bibliográfico, obtivemos fontes de referência em livros e textos que tratam de gestão educacional e aspectos afins. Quanto à pesquisa documental, buscamos, entre outros, a Constituição Federal de 1988, a Lei de Diretrizes e Bases da Educação Nacional n9394/96 e a legislação educacional alagoana, homologada pela rede pública estadual que trata da implantação da gestão democrática, sendo elas:

- Carta de Princípios da Educação Construindo a Escola Cidadã. Secretaria de Educação de Alagoas. Coordenadora de Gestão Escolar. Maceió, AL, 2000a.

- Lei no 5945, de 25 de ago. de 1997. Dispõe sobre a criação dos conselhos interativos das escolas da rede pública estadual de ensino e dá providências correlatas. Maceió, AL, ago. 1997.

- Lei $n^{\circ}$ 6.152, de 11 de maio de 2000. Institui a gestão democrática na rede pública estadual de ensino, como espaço de participação e construção coletiva, através de eleições diretas para diretores e diretoresadjuntos das escolas de educação básica e dá providências correlatas. Gabinete civil. Maceió, AL, Mai 2000b.

- Lei no 6.196, de 26 de set. de 2000. Dispõe sobre o Estatuto do Magistério Público do Estado de Alagoas e adota providências correlatas. Gabinete civil. Maceió, $A L$, set 2000 c.

- Decreto no 203, de 20 de jun. de 2001. Dispõe sobre a regulamentação da lei no 6.152, de 11 de maio de 2000. Gabinete civil. Maceió, AL, jun, 2001.

- Decreto no 36.586, de 06 de jul. de 1995. Incentiva a criação de caixas escolares, sob a forma de sociedade civil, nas unidades da pré-escola e do 10 e 10 graus da rede estadual de ensino. Gabinete civil. Maceió, AL, 1995.

- Plano Estadual de Educação de Alagoas. PEE 2006/2015, Maceió. Secretaria Executiva de Educação, Comitê Gestor do Plano Estadual de Educação, 2006.

- Plano Estadual de Educação de Ala- 
goas. PEE 1998 /2007, Maceió. Secretaria Executiva de Educação, Comitê Gestor do Plano Estadual de Educação, 1998.

A partir de análise qualitativa do texto do arcabouço legal acima exposto, a pesquisa documental foi realizada. Através deles desbravamos os caminhos e legitimidade da implantação da gestão democrática nas escolas públicas estaduais em Alagoas, verificando as possíveis contribuições e entraves desse modelo. Observamos ainda, aspectos sobre a escolha de diretores, a participação da comunidade escolar na construção do princípio democrático na escola, a contribuição da legislação educacional na construção de uma cultura organizacional baseada na coletividade e no comprometimento para a qualidade da oferta do ensino público. Enfim, elaboramos uma análise interpretativa dos textos legais.

\section{APRESENTAÇÃO DO ESTUDO}

\subsection{Caminhos da Gestão Democrática em}

\section{Alagoas}

Percebe-se que aproximadamente após 12 anos da regulação da gestão democrática no ensino público pela Carta Magna, é que dar-se início ao processo da implantação do modelo na rede estadual de ensino em Alagoas. O processo de efetivação, ocorre, mais especificamente, em 1999 quando da realização, no dia 14 de dezembro, no I Congresso Constituinte Escolar - CECEAL - com representatividade de diversos segmentos da comunidade educacional. Esse foi o primeiro passo em Alagoas em busca da implantação da gestão democrática nas escolas pertencentes à rede pública estadual de educação. Contudo, antes desse momento democrático o governo buscou formas autoritá- rias para implantar a gestão democrática, que ao que parece, era motivado pelo poder econômico.

\subsection{Caixa Escolar / Conselho Escolar - exer- cício de autonomia?}

Nos anos que antecederam a construção da Carta de Princípios da Educação, alguns mecanismos buscavam a participação da comunidade escolar sob a forma do Decreto no 36.586, de 06 de julho de 1995, que incentivou a criação dos caixas escolares e dava a cada escola a responsabilidade de administrar e fiscalizar as verbas disponibilizadas democraticamente. Portanto era urgente essa funcionalidade educativa. Por isso, a força do Decreto! Bem como afirma Silva (2016) a implantação da gestão, em muitos casos, deixou de ser um desejo da coletividade, para ser uma imposição governamental impulsionada pela força financeira. A saber:

Após a Lei 9394/96, as discussões acerca do assunto passaram a ser mais frequentes, criando o governo formas diversas de divulgação, usando os mesmos mecanismos de estudos já indicados neste trabalho, elaborando manuais de orientações e outros. No que se percebe, nenhum mecanismo fora tão forte e contundente como o posto na referida lei em seu artigo 12, inciso II: "administrar seu pessoal e seus recursos materiais e financeiros". Com esta descentralização estava posta a condição para que não fosse negada a implantação da gestão democrática, desse modo, dois sentimentos reforçaram essa implantação: o da responsabilização pelos descontos financeiros da instituição ou da atração em administrar os recursos. Foi assim implantada a gestão democrática na maioria das redes públicas brasileiras, sob o prisma do poder econômico. (SILVA, 2016, p. 8)

https://periodicos.unifap.br/index.php/estacao Macapá, v. 8, n. 1, p. 21-30, jan./abr. 2018 
Como podemos perceber, o Decreto por si só é um documento autoritário. Ele não requer discussões da sociedade. É publicado para ser cumprido.

\subsection{Lei Estadual no 5.945, de 25 de agosto de 1997}

Mais tarde, em 1997, foram criados os conselhos escolares por meio da Lei Estadual no 5.945, de 25 de agosto de 1997, que tinha como finalidade "promover a integração do estado, da sociedade e da comunidade escolar, visando à gestão democrática do ensino público e ao exercício da cidadania" (ALAGOAS, 1997).

O conselho escolar compõe a organização da gestão democrática escolar (SILVA, 2012). Cabe a esse órgão

zelar pela manutenção da escola e participar da gestão administrativa, pedagógica e financeira, contribuindo com as ações dos dirigentes escolares a fim de assegurar a qualidade de ensino. Eles têm funções deliberativas, consultivas, fiscais e mobilizadoras, garantindo a gestão democrática nas escolas públicas. (Brasil, 2004).

A criação dos conselhos escolares tornou-se marco da gestão democrática, pois independentemente da forma de como de escolhe o diretor, esse órgão colegiado tem que existir na administração da escola pública em todo o Brasil. É bem verdade que assim como todo e qualquer órgão colegiado, pode apresentar problemas e não desenvolver a sua função a contento, mas temos a certeza que representa um avanço na educação. Eles são um reforço da correlação da democracia escolar com o financeiro.

\subsection{A carta de princípios - passos iniciais à democratização escolar}

Em 1999, as discussões em torno da democratização da gestão educacional em Alagoas, para a rede púbica estadual, se acentuaram, alicerçadas pela política do governo eleito nesta época no estado, culminando na realização, no dia 14 de dezembro deste mesmo ano, do primeiro Congresso Constituinte Escolar. Participaram do Congresso delegados regionais, educadores e indivíduos da sociedade civil, oportunidade em que foram apresentadas e discutidas as propostas. Estas obedeciam as adaptações que os sistemas educacionais deveriam fazer, conforme as exigências do MEC e da legislação educacional, concernentes aos seus princípios. Isto nos faz refletir, que a há uma necessidade e importância para que a escola seja autônoma, mas ela precisa ser a partir das propostas trazidas pelos participantes com fundamentação no arcabouço legal a nível nacional, foram debatidas e posteriormente, aprovadas em plenária. Constitui-se assim, de forma democrática, a partir da sociedade, o texto da Carta de Princípios.

Assim, a Carta de Princípios da Educação (ALAGOAS, 2000), representada pela vontade coletiva de ampliação dos espaços de participação e autonomia da comunidade educativa, organizou-se com base em três eixos: educacional, pedagógico e relacional. Os componentes destes três eixos resultaram numa seleção de 68 princípios que, pela sua aprovação em plenária, se constituíram em elemento norteador de toda a política educacional do Estado de Alagoas. No escopo deste documento, encontra-se fundamentada uma educação voltada para o coletivo, priorizado a dialogicidade e o res- 
peito a todos os sujeitos sociais que, imbuídos de força política, podem transformar a realidade posta (ALAGOAS, 1999).

\subsection{O Estatuto do Magistério Público Esta- dual de Alagoas - a gestão democrática alicerçada}

Em Alagoas, o processo de democratização das escolas públicas começa a tomar forma ao partir do Estatuto do Magistério Público Estadual (ALAGOAS, 2000b) Este documento legal instituiu a gestão democrática na rede pública estadual de ensino, como espaço de participação e construção coletiva, através de eleições diretas para a chapa de diretores e diretores-adjuntos das escolas públicas do Estado, tendo sido regulamentada pelo Decreto no 203, de 20 de junho de 2001. Em consonância com a Lei 6.152/2000, o Estatuto do Magistério Público do Estado de Alagoas (Lei Ordinária $\mathrm{n}^{\circ}$ 6.196, de 26.09.200, alterada pela Lei $n^{\circ}$ 6.761 de 04.08.2006) ratifica as eleições para diretores como instrumento de participação e construção coletiva.

As concepções de democracia engendradas neste contexto são resultados de pequenas manifestações para democratizar a rede de ensino que tinham o propósito de mobilizar os sujeitos envolvidos no universo escolar na perspectiva da participação e na tomada de decisões, tendo como compromisso a melhoria da educação pública alagoana (CRUZ NETO, 2008).

\subsection{Plano Estadual de Educação (1998- 2007) - um retrocesso às práticas democrá- ticas?}

Seguindo o mesmo rumo, foi criado o Plano Estadual de Educação 1998-2007 (A-
LAGOAS, 1998) a fim de nortear as ações nas instâncias educacionais de Alagoas, porém, este não contemplou a participação da sociedade civil organizada, interessada na educação, mas restringiu-se à Secretaria Estadual de Educação (SEE) e instituições estaduais e municipais intermediárias, demonstrando, mais uma vez, o seu caráter centralizador na estrutura da SEE.

O processo de democratização nas escolas da rede pública estadual em Alagoas, precisava agora ser contemplado na sua forma concreta e efetivado nas escolas públicas alagoanas, em resposta aos novos desafios colocados pela contemporaneidade, exigindo da escola uma nova postura de autonomia e participação em sua organização.

É importante que a gestão democrática cresça junto com a sociedade, que traga debates benéficos, que se fortaleça, com a colaboração da legislação educacional, se constitua em verdadeira política de Estado, e que, partindo dessa grande célula que são os espaços escolares, possamos construir uma sociedade firme em seus propósitos de lutas justas de igualdade e oportunidades para todos.

\section{CONSIDERAÇÕES FINAIS}

O processo de gestão escolar tem sofrido crescentes mudanças nas últimas décadas, desde a promulgação da Constituição Brasileira de 1988. Segue-se uma nova orientação de gestão, dentro dos princípios democráticos, exigindo o envolvimento do poder público e uma permanente participação de todos os segmentos, interno e externo à escola, nas tomadas de decisões, a fim de se construir a escola pública de qualidade.

São muitos os desafios que se apresen- 
tam para a efetivação da gestão democrática, porém os caminhos para superá-los também se apresentam nas mais variadas formas. A legislação educacional surge como uma aliada nesse processo à medida que orienta e direciona as ações.

Não há como pensar a escola sem que esta seja vista como uma unidade social, com suas características peculiares e as condições sociais que a definem. Conhecer essa realidade é fundamental para entender os problemas e dificuldades do dia a dia e, assim, poder se pensar em alternativas que ajudem no desenvolvimento pleno de cada instituição de ensino. Esse desenvolvimento pleno "caracteriza-se por uma força de atuação consistente pela qual os membros da escola reconhecem e assumem seu poder de exercer influência na dinâmica dessa unidade social, de sua cultura e dos seus resultados." (LÜCK, 2000, p. 27).

Nós temos a percepção de que a força da legislação reguladora e regulamentado foi crucial para a implementação da gestão democrática nas escolas, sobretudo, em Alagoas. Entretanto, ainda há muito a se fazer. Como já foi dito anteriormente, a gestão democrática da escola pública é um dos instrumentos que podem garantir que as lutas pela educação não esmoreçam, na medida em que é a participação coletiva que vai proporcionar a análise e a compreensão dos desafios e problemas a serem superados pela educação.

Conhecer a legislação educacional é primordial para utilizá-la como mecanismo para se fazer valer os direitos da comunidade escolar, buscar a realização de seus anseios e contribuir com a sociedade na construção de uma educação com qualidade em Alagoas e no Brasil como um todo, mas sob a perspectiva dos que fazem a escola, e não sob as perspectivas daqueles que não se importam com ela.

\section{REFERÊNCIAS}

ALAGOAS. Carta de Princípios da Educação - Construindo a Escola Cidadã. Secretaria de Educação de Alagoas. Coordenadora de Gestão Escolar. Maceió, AL, 2000a. . Lei no 5945, de 25 de ago. de 1997. Dispõe sobre a criação dos conselhos interativos das escolas da rede pública estadual de ensino e dá providências correlatas. Maceió, AL, ago, 1997.

. Lei $n^{\circ} 6.152$, de 11 de maio de 2000. Institui a gestão democrática na rede pública estadual de ensino, como espaço de participação e construção coletiva, através de eleições diretas para diretores e diretores-adjuntos das escolas de educação básica e dá providências correlatas. Gabinete civil. Maceió, AL, Mai 2000b.

. Lei no 6.196, de 26 de set. de 2000.

Dispõe sobre o Estatuto do Magistério Público do Estado de Alagoas e adota providências correlatas. Gabinete civil. Maceió, $\mathrm{AL}$, set $2000 \mathrm{c}$.

. Decreto no 203, de 20 de jun. de 2001. Dispõe sobre a regulamentação da lei $n$ - 6.152, de 11 de maio de 2000. Gabinete civil. Maceió, AL jun, 2001.

. Decreto no 36.586, de 06 de jul. de 1995. Incentiva a criação de caixas escolares, sob a forma de sociedade civil, nas unidades da pré-escola e do 10 e 10 graus da rede estadual de ensino. Gabinete civil. Maceió, AL, 1995.

Plano Estadual de Educação [de Alagoas]: PEE 2006/2015. Maceió: Secretaria Executiva de Educação, Comitê Gestor do Plano Estadual de Educação, 2006.

. Plano Estadual de Educação de

https://periodicos.unifap.br/index.php/estacao Macapá, v. 8, n. 1, p. 21-30, jan./abr. 2018 
Alagoas. PEE 1998 /2007, Maceió. Secretaria Executiva de Educação, Comitê Gestor do Plano Estadual de Educação, 1998.

BRASIL. Constituição (1988). Constituição da República Federativa do Brasil. Brasília, DF: Senado Federal: Centro Gráfico, 1988. . Lei no 9.394 de 20 de dezembro de 1996. Estabelece as Diretrizes e Bases da Educação Nacional. Brasília, DF, Gabinete Civil, 2016.

- Cadernos do MEC. Programa de fortalecimento nacional dos conselhos escolares. Brasília: MEC, 2004.

. Lei no 10172/01. Dispõe sobre o Plano Nacional de Educação (2001/2011). Brasília: Gabinete Civil, 2001.

. Lei no 13005. Dispõe sobre o Plano Nacional de Educação (2014/2024). Brasília: Gabinete Civil, 2014.

COSTA, J. L. F. S, ROCHA, C. M. A responsabilização dos atores na implementação da gestão democrática em uma escola estadual: um estudo de caso. Monografia (Graduação em Pedagogia) - Universidade Estadual de Alagoas, Palmeira dos Índios, 2011.

CRUZ NETO, T. L. A implantação da gestão educacional democrática na rede pública estadual de ensino de Alagoas: da concepção à carta de princípios. In: Planejamento educacional e participação democrática: um estudo sobre a rede pública estadual de ensino. Maceió, 2008.

HORA, D. L. Educação e gestão educacional na sociedade brasileira contemporânea: algumas reflexões. Revista do Programa de Mestrado em Educação e Cultura, Florianópolis, v.4, n. 2, pp189-209, dez., 2003.

LÜCK, H. Perspectivas da gestão escolar e implicações quanto à formação de seus gestores. Em Aberto. Brasília, v. 17, n. 72, p. 11-33, fev./jun. 2000.

PARO, V. H. Implicações do caráter político da educação para a administração da escola pública. Educação e Pesquisa. São Paulo, v. 28, n. 2. p. 11-23, jul./dez. 2002.

SILVA, R. M. Processo histórico e político da gestão democrática escolar no Brasil. Revista de Educação, Ciências e Matemática, v.6, n. 2, 2016.

. Gestão democrática escolar globalizada/legalizada - um estudo entre Brasil e Portugal. Estação Científica (UNIFAP), v. 5, n. 1, p. 115-125, jan./jun. 2015.

Globalização e gestão escolar no Brasil e em Portugal. Dissertação de Mestrado. Centro de Educação. Universidade de Aveiro, Portugal, 2012.

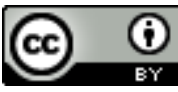

License information: This is an openaccess article distributed under the terms of the Creative Commons Attribution License, which permits unrestricted use, distribution, and reproduction in any medium, provided the original work is properly cited.

Artigo recebido em 16 de março de 2017.

Avaliado em 15 de dezembro de 2017.

Aceito em 30 de janeiro de 2018.

Publicado em 25 de maio de 2018.

\section{Como citar este artigo (ABNT):}

SILVA, Rosilânia Macedo da; COSTA, Jacqueline Lemos Fontes Silva. A gestão democrática nas escolas públicas estaduais em Alagoas: um olhar com base nos marcos regulatórios. Estação Científica (UNIFAP), Macapá, v. 8, n. 1, p. 21-30, jan./abr. 2018. 